Wright State University

CORE Scholar

Mechanical and Materials Engineering Faculty

Publications

Mechanical and Materials Engineering

$2-2012$

\title{
Evaluating Superconducting Ybco Film Properties Using Xray Photoelectron Spectroscopy
}

Paul N. Barnes

Justin C. Tolliver

Timothy J. Haugan

Sharmila M. Mukhopadhyay

Wright State University - Main Campus, sharmila.mukhopadhyay@wright.edu

John T. Grant

University of Dayton

Follow this and additional works at: https://corescholar.libraries.wright.edu/mme

Part of the Materials Science and Engineering Commons, and the Mechanical Engineering Commons

\section{Repository Citation}

This Article is brought to you for free and open access by the Mechanical and Materials Engineering at CORE Scholar. It has been accepted for inclusion in Mechanical and Materials Engineering Faculty Publications by an authorized administrator of CORE Scholar. For more information, please contact library-corescholar@wright.edu. 


\section{AFRL-RZ-WP-TP-2012-0093}

\section{EVALUATING SUPERCONDUCTING YBCO FILM PROPERTIES USING X-RAY PHOTOELECTRON SPECTROSCOPY (POSTPRINT)}

Paul N. Barnes, Justin C. Tolliver, and Timothy J. Haugan

Mechanical Energy Conversion Branch

Energy/Power/Thermal Division

Sharmila M. Mukhopadhyay

Wright State University

John T. Grant

University of Dayton

FEBRUARY 2012

Approved for public release; distribution unlimited. See additional restrictions described on inside pages

\section{STINFO COPY}

(C) 2004 The American Ceramic Society

AIR FORCE RESEARCH LABORATORY

PROPULSION DIRECTORATE

WRIGHT-PATTERSON AIR FORCE BASE, OH 45433-7251

AIR FORCE MATERIEL COMMAND

UNITED STATES AIR FORCE 


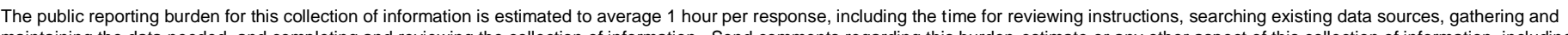

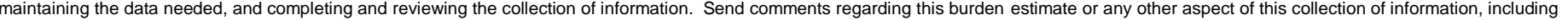

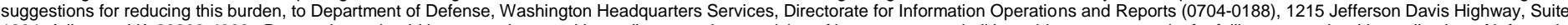

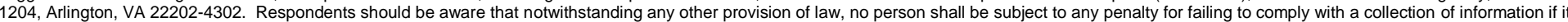
does not display a currently valid OMB control number. PLEASE DO NOT RETURN YOUR FORM TO THE ABOVE ADDRESS.
1. REPORT DATE (DD-MM-YY)
2. REPORT TYPE
3. DATES COVERED (From - To)
February 2012
Conference Paper Postprint
01 January 2002 - 01 January 2004

\section{TITLE AND SUBTITLE}

EVALUATING SUPERCONDUCTING YBCO FILM PROPERTIES USING X-RAY

PHOTOELECTRON SPECTROSCOPY (POSTPRINT)

5a. CONTRACT NUMBER

In-house

5b. GRANT NUMBER

5c. PROGRAM ELEMENT

NUMBER

$62203 \mathrm{~F}$

\section{AUTHOR(S)}

Paul N. Barnes, Justin C. Tolliver, and Timothy J. Haugan (AFRL/RZPG)

Sharmila M. Mukhopadhyay (Wright State University)

John T. Grant (University of Dayton)

\section{PERFORMING ORGANIZATION NAME(S) AND ADDRESS(ES)}

Mechanical Energy Conversion Branch (AFRL/RZPG) |Wright State University

Energy/Power/Thermal Division

Air Force Research Laboratory

Propulsion Directorate

Wright-Patterson Air Force Base, OH 45433-7251

Air Force Materiel Command, United States Air Force
Russ Engineering Center

Dayton, $\mathrm{OH} 45435$

University of Dayton

300 College Park

Dayton, OH 45469

\section{SPONSORING/MONITORING AGENCY NAME(S) AND ADDRESS(ES)}

Air Force Research Laboratory

Propulsion Directorate

Wright-Patterson Air Force Base, OH 45433-7251

Air Force Materiel Command

United States Air Force

5d. PROJECT NUMBER

3145

5e. TASK NUMBER

32

5f. WORK UNIT NUMBER

$314532 Z 9$

8. PERFORMING ORGANIZATION REPORT NUMBER

AFRL-RZ-WP-TP-2012-0093

10. SPONSORING/MONITORING AGENCY ACRONYM(S)

AFRL/RZPG

11. SPONSORING/MONITORING AGENCY REPORT NUMBER(S)

AFRL-RZ-WP-TP-2012-0093

12. DISTRIBUTION/AVAILABILITY STATEMENT

Approved for public release; distribution unlimited.

13. SUPPLEMENTARY NOTES

Conference paper published in the proceedings of the Fabrication of Long-Length and Bulk High-Temperature

Superconductors. The conference was the 105th annual meeting of The American Ceramic Society, held April 27-30, 2003, in Nashville, TN. (C) 2004 The American Ceramic Society. The U.S. Government is joint author of the work and has the right to use, modify, reproduce, release, perform, display, or disclose the work. Work on this effort was completed in 2004.

PA Case Number: ASC-03-2986; Clearance Date: 06 Dec 2004.

14. ABSTRACT

Initial results have been recently reported that suggest a potential correlation exists between the full-width-halfmaximum (FWHM) of the $\mathrm{Y}(3 \mathrm{~d})$ peak obtained by $\mathrm{x}$-ray photoelectron spectroscopy (XPS) and the critical current density a $\mathrm{YBa}_{2} \mathrm{Cu}_{3} \mathrm{O}_{7-\mathrm{x}}$ film can carry. In particular, the $\mathrm{Y}\left(3 \mathrm{~d}_{5 / 2}\right)$ demonstrated a stronger correlation. Transport currents were determined by the 4-point contact method using the $1 \mu \mathrm{V} / \mathrm{cm}$ criterion. An apparent correlation was also suggested between the Y(3d) FWHM and ac loss data points were acquired to further test the usefulness of the correlations. Samples were created by pulsed laser deposition of $\mathrm{YBa}_{2} \mathrm{Cu}_{3} \mathrm{O}_{7-\mathrm{x}}$ on $\mathrm{LaAlO}_{3}$ substrates.

15. SUBJECT TERMS

$\mathrm{X}$-ray, transport currents, ac loss, data points, samples, pulsed laser deposition, substrates

16. SECURITY CLASSIFICATION OF:

\section{a. REPORT} b. ABSTRACT Unclassified c. THIS PAGE

Unclassified

17. LIMITATION
OF ABSTRACT:
SAR

SAR
18. NUMBER OF PAGES

16 19a. NAME OF RESPONSIBLE PERSON (Monitor)

Timothy J. Haugan

19b. TELEPHONE NUMBER (Include Area Code) N/A 


\section{EVALUATING SUPERCONDUCTING YBCO FILM PROPERTIES USING X- RAY PHOTOELECTRON SPECTROSCOPY}

Paul N. Barnes, Justin C. Tolliver, and Timothy J. Haugan

Air Force Research Laboratory

AFRL/PRPG, Building 450

Wright-Patterson AFB, OH 45433

Sharmila M. Mukhopadhyay

Wright State University

Russ Engineering Center

Dayton, $\mathrm{OH} 45435$
John T. Grant

University of Dayton

300 College Park

Dayton, OH 45469

\section{ABSTRACT}

Initial results have been recently reported that suggest a potential correlation exists between the full-width-half-maximum (FWHM) of the Y(3d) peak obtained by x-ray photoelectron spectroscopy (XPS) and the critical current density a $\mathrm{YBa}_{2} \mathrm{Cu}_{3} \mathrm{O}_{7-\mathrm{x}}$ film can carry. In particular, the $\mathrm{Y}\left(3 \mathrm{~d}_{5 / 2}\right)$ demonstrated a stronger correlation. Transport currents were determined by the 4-point contact method using the $1 \mu \mathrm{V} / \mathrm{cm}$ criterion. An apparent correlation was also suggested between the Y(3d) FWHM and ac loss data from magnetic susceptibility measurements. In this report, a few additional data points were acquired to further test the usefulness of the correlations. Samples were created by pulsed laser deposition of $\mathrm{YBa}_{2} \mathrm{Cu}_{3} \mathrm{O}_{7-\mathrm{x}}$ on $\mathrm{LaAlO}_{3}$ substrates.

\section{INTRODUCTION}

Significant progress has been made in the development of the high temperature superconducting (HTS) $\mathrm{YBa}_{2} \mathrm{Cu}_{3} \mathrm{O}_{7-\mathrm{x}}$ (YBCO) coated conductors. ${ }^{1-4}$ These achievements have been accomplished by using a variety of techniques investigating multiple aspects of the conductor architecture and growth. ${ }^{5-6}$ Successful long length development of the YBCO coated conductor will result in its availability for use in a variety of commercial applications such as power transmission cables, high field magnets, transformers, high power generators and motors, etc.

To the extent authorized under the laws of the United States of America, all copyright interests in this publication are the property of The American Ceramic Society. Any duplication, reproduction, or republication of this publication or any part thereof, without the express written consent of The American Ceramic Society or fee paid to the Copyright Clearance Center, is prohibited. 
However, many improvements can still be made in the properties of the coated conductor as well as production of longer lengths. ${ }^{7-9}$ Continuing development of the coated conductor necessitates not only a detailed study of deposition techniques, source materials, deposition conditions, and substrates employed, but also characterization of the final deposited films. A technique used in this paper is X-ray photoelectron spectroscopy (XPS), especially of the YBCO layer. XPS was used to investigate the chemical and microstructural profiles of YBCO coated conductor samples. ${ }^{10-11}$ Use of the technique can give consideration to interfacial issues and determine composition and chemistry at different depths in the conductor architecture.

\section{BACKGROUND}

Comparison of the XPS spectra for the various constituents of YBCO coated conductor samples revealed that the $\mathrm{Y}(3 \mathrm{~d})$ photoelectron peak shape observed from the YBCO layer differed among various samples investigated. ${ }^{10-11}$ This difference in XPS peak shape may indicate that there could be some difference in the atomic co-ordination between the samples. The observed difference, when compared to the particular film's properties, may also indicate the possibility of a correlation with the particular quality of the film.

In a previous study by Beyer et al., ${ }^{12}$ a difference in samples was also noted that depended on the particular substrate used. In this study, two series of samples were prepared by hollow cathode sputtering of the YBCO film, between $100 \mathrm{~nm}$ to $300 \mathrm{~nm}$ thick. One series was grown on (100) $\mathrm{MgO}$ and the other on (001) YSZ buffered r-plane sapphire. The $\mathrm{T}_{\mathrm{c}} \mathrm{s}$ were typically between $80-91 \mathrm{~K}$, a wide variance by recent deposition standards. During the various treatments, the $\mathrm{Y}$ emission remained fairly stable, but the $\mathrm{Ba}\left(3 \mathrm{~d}_{5 / 2}\right)$ structure showed distinct differences in its lineshape in the YBCO deposited on the two different substrates. Beyer at al. noted that the differences were not caused by surface impurities but were characteristic of the samples. A structural deviation was assumed to be responsible for the difference. Even so, this does not rule out that the differences might correlate to the film's current transport properties since some substrates indeed provide better subsequent films than others.

Another possible correlation cited in the previous work is the relationship of the Y(3d) peak FWHM and the samples ac loss data from magnetic susceptibility measurements. It has been previously observed that with widening of the temperature-dependent ac susceptibility curves with increasing applied magnetic field the quality of the YBCO film generally decreases. ${ }^{13}$ However, a documented study of this correlation to current transport properties using the loss component of ac susceptibility data has not been published, making it unclear how effective this correlation is. ${ }^{14}$ Even so, the relationship between the Y(3d) peak FWHM and the $\Delta \mathrm{T}$ of the magnetic field lines reinforces the possibility. In this case, $\Delta \mathrm{T}$ of the magnetic field lines refers to either the difference between the temperatures at which the maxima in the ac loss occurs for the 0.025 and 2.2 Oe applied magnetic 
fields (peak to peak of $\chi^{\prime \prime}$ ) or to the FWHM of the $2.2 \mathrm{Oe}$ (in particular) magnetic field data $\chi^{\prime \prime}$ vs. T

\section{EXPERIMENTAL}

In this study, samples were created by pulsed laser deposition of $\mathrm{YBCO}$ on single crystal $\mathrm{LaAlO}_{3}$. Previously, most samples were made in the same manner although other samples are included such as YBCO on buffered metallic tape and buffered single crystals. ${ }^{10}$ The laser ablation was accomplished using a Lambda Physik LPX $305 \mathrm{i}$ excimer laser at the $\mathrm{KrF}$ transition, $\lambda=248 \mathrm{~nm}$ with a $25 \mathrm{~ns}$ pulse width. Mounting of the substrates in the deposition chamber was accomplished using silver paste. Specific details of the deposition conditions were given previously. ${ }^{10}$ The YBCO layers of the newly created samples were between 0.25 to 0.40 micrometers thick.

Since the previous study contained data representing a limited number of low quality samples, i.e. $\mathrm{J}_{\mathrm{c}}<10^{6} \mathrm{~A} / \mathrm{cm}^{2}$, the three samples used here were particularly chosen for this study due to their poor film quality. One sample was unintentionally made with low quality and the other two were intentionally made so by specifically reducing the deposition temperature in the PLD chamber by $\sim 100^{\circ} \mathrm{C}$. The critical transition temperature $\left(\mathrm{T}_{\mathrm{c}}\right)$ of $\mathrm{YBCO}$ was measured by ac magnetic susceptibility and the critical current density $\left(\mathrm{J}_{\mathrm{c}}\right)$ by four-contact transport current measurement.

The composition and chemistry of each sample was measured by X-ray photoelectron spectroscopy (XPS) using a Kratos AXIS Ultra. The monochromatic $\mathrm{Al} \mathrm{K}_{\alpha} \mathrm{X}$-ray line was used for enhanced spectral resolution. The analysis spot size was approximately $110 \mu \mathrm{m}^{2}$. An electron flood charge neutralizer was used during analysis to avoid charge build-up differences between different surfaces (if any). Ion beam sputtering was performed using a mini-beam ion gun. $\mathrm{Ar}^{+}$ions were used at an energy of $3 \mathrm{keV}$. In the raster setting used, the sputtered area was approximately a $1 \mathrm{~mm} \times 0.5 \mathrm{~mm}$ elliptical region, several times larger than the spot size analyzed by XPS. Spectroscopic analysis was performed on as received surfaces and after subsequent sputtering to avoid the influence of surface contamination or any chemical reactivity with air.

\section{RESULTS AND DISCUSSION}

The $\mathrm{J}_{\mathrm{c}} \mathrm{S}$ of the samples were $1.5 \times 10^{5} \mathrm{~A} / \mathrm{cm}^{2}$ for the unintentionally made poor sample, $2 \times 10^{5} \mathrm{~A} / \mathrm{cm}^{2}$ for the one low deposition temperature sample and $<10^{4}$ $\mathrm{A} / \mathrm{cm}^{2}$ for the other low deposition temperature sample. All three YBCO samples in this study had a reduced $T_{c}$. Refer to Figure 1 for the low temperature deposition sample with the higher critical current density. The $T_{c}$ for the sample made with the normal deposition temperature had a $T_{c}$ of $\sim 86.1 \mathrm{~K}$. Since samples were exposed to air the top surface was removed by sputtering. The before and after sputtering values obtained by XPS are largely uncorrelated as evidenced by 


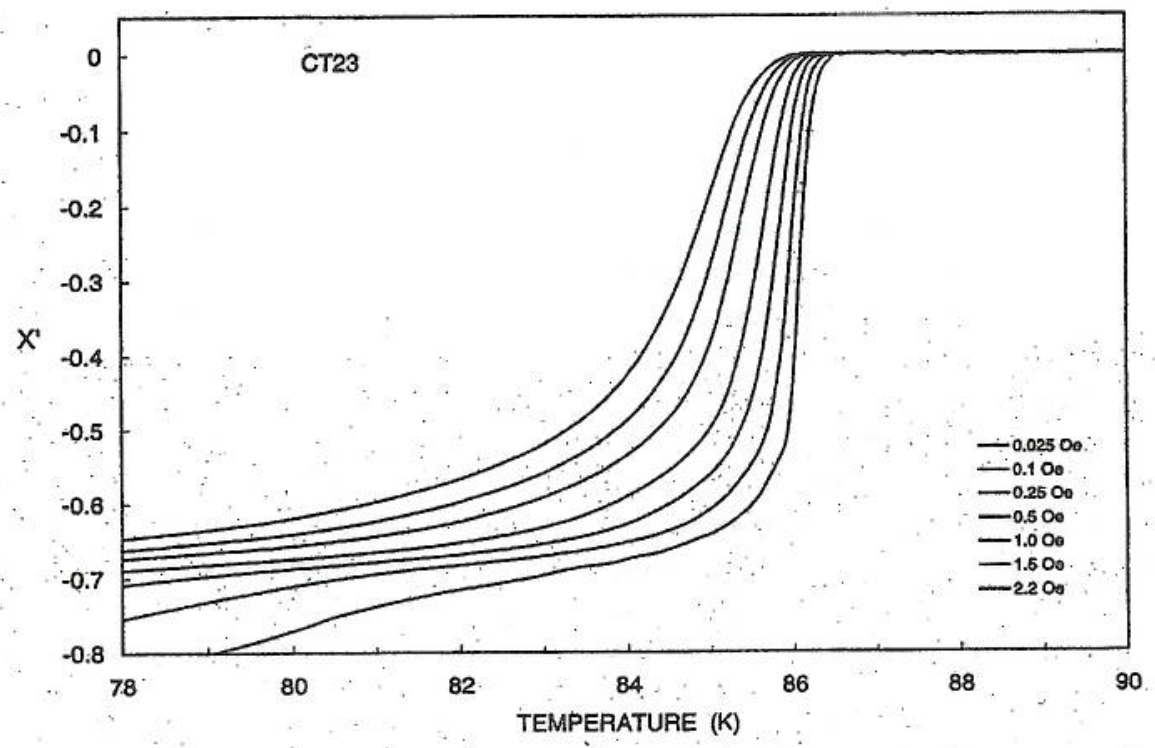

Fig. 1. The ac susceptibility data for sample CT23 made with the low deposition temperature but had a nominal $J_{c}$ of $2 \times 10^{5} \mathrm{~A} / \mathrm{cm}^{2}$. The different curves result from the different applied fields listed in the legend-the field increases from right to left.

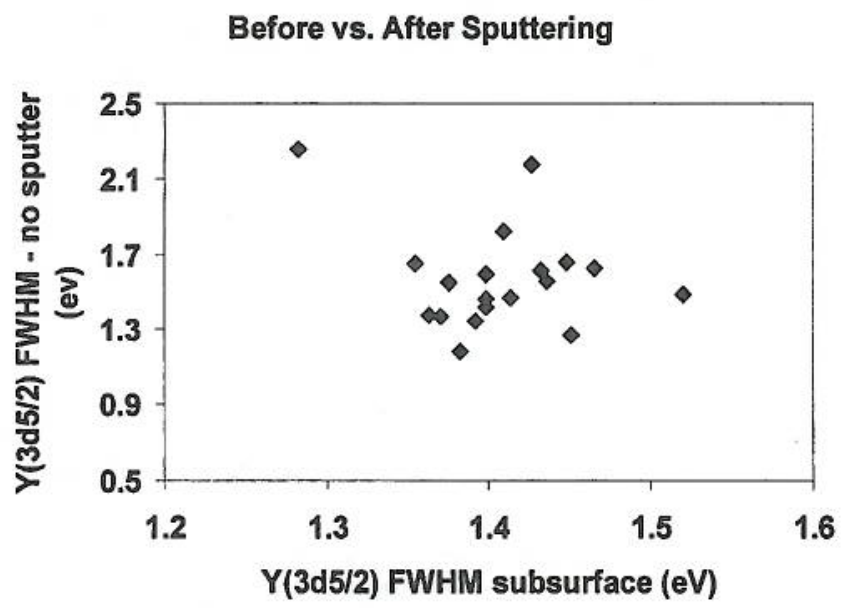

Fig. 2. Comparison of XPS data taken before and after sputtering of the surface for contaminate removal. 
the scatter of the data given in Figure 2 which shows values for all samples included in the previous study, although not reported there.

In Figure 3, the relative peak intensity ratios of all samples for both studies are shown. The two stray points depicted were the two that were intentionally made poor by lowering the deposition temperature. Since all other samples had similar peak intensity ratios, it is likely that the difference caused by the low deposition temperature is due to inclusions and alternate phases incorporated during

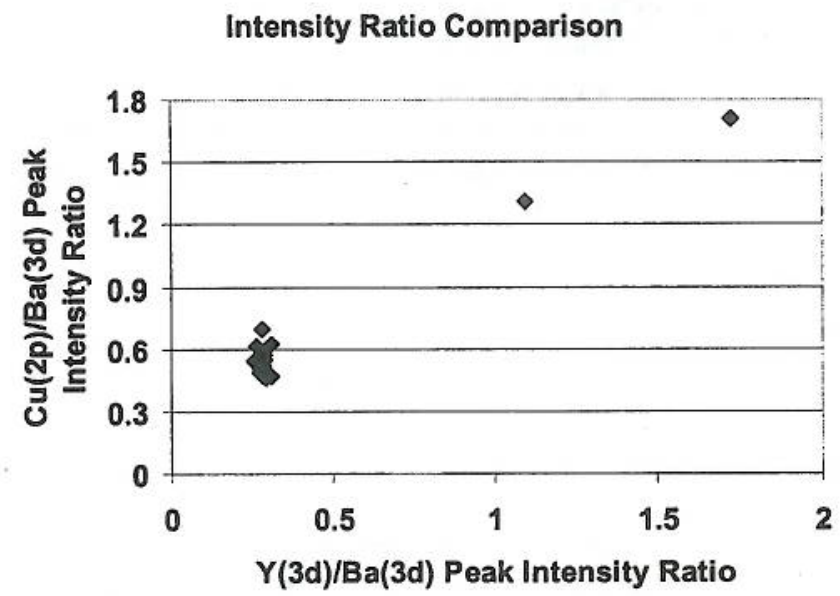

Fig. 3. Comparison of the relative XPS peak intensities of the various samples. The two compositionally stray points were made with the low deposition temperature.

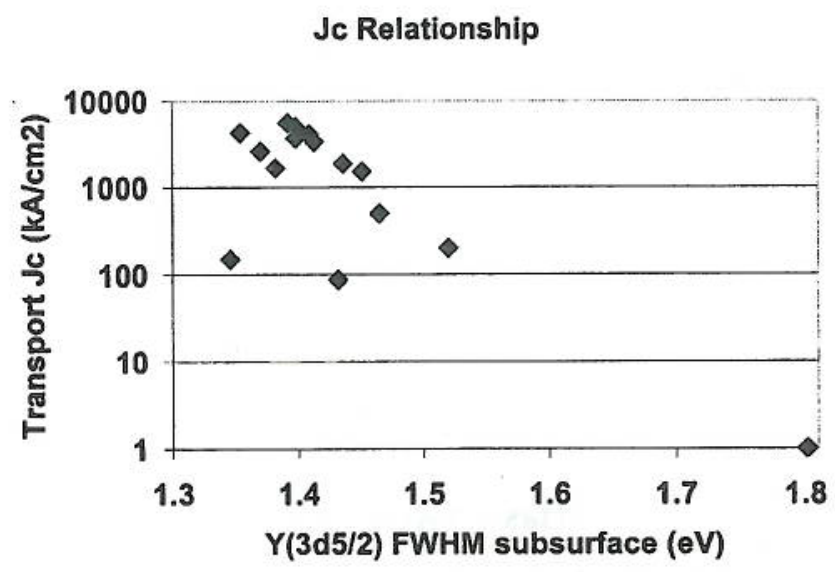

Fig. 4. Comparison of the $\mathrm{Y}\left(3 \mathrm{~d}_{5 / 2}\right)$ peak FWHM and transport $\mathrm{J}_{\mathrm{c}}$.

5

Approved for public release; distribution unlimited

Fabrication of High-Temperature Superconductors 
deposition. As such, these compositionally stray points will be excluded from the correlation charts as being invalid for comparison.

In Figure 4 the correlation of the FWHM for the $\mathrm{Y}\left(3 \mathrm{~d}_{5 / 2}\right)$ peak and the critical transport current density (four point resistive) is given. The new point provided by the additional sample is located at $1.35 \mathrm{eV}$ FWHM Y $\left(3 \mathrm{~d}_{5 / 2}\right)$ with $0.15 \mathrm{MA} / \mathrm{cm}^{2}$. For the given plot, this data resulted in a stray point from the other points which indicate a correlation. The point located at $1.8 \mathrm{eV}$ is not stray since it fits the pattern of low $\mathrm{J}_{\mathrm{c}}$ correlated to a larger $\mathrm{Y}\left(3 \mathrm{~d}_{5 / 2}\right) \mathrm{FWHM}$. It is not clear if the lower transport current was a result of cracks in the film which can cause a lower transport current and yet not affect the XPS spectra. However, it is interesting to note that this sample also resulted in a stray point to a greater degree on the following figure, Figure 5, which gives the relationship between the FWHM for the $\mathrm{Y}\left(3 \mathrm{~d}_{5 / 2}\right)$ peak and the FWHM of the critical transition temperature by susceptibility measurement.

Figure 5 depicts the relationship between the FWHM for the $\mathrm{Y}\left(3 \mathrm{~d}_{5 / 2}\right)$ peak and the FWHM of the 2.2 Oe magnetic field line at the critical transition temperature by ac susceptibility measurement. As previously mentioned, the new data point on this plot $(5 \mathrm{~K}$ for $\Delta \mathrm{T})$ also strayed from the others based on the expected relationship. Exactly why there is a corroborative stray form the original data in both graphs is not clear, but a correlation between the points apparently still exists. This clearly indicates the need for additional data to determine the effectiveness of the correlations as well as determining the exact relationship of the two plots presented here. Figure 6 shows the $\chi^{\prime \prime}$ susceptibility data for sample CT23, from Figure 1, from which the FWHM for the $\mathrm{Y}(3 \mathrm{~d} 5 / 2)$ peak was derived. The FWHM of the 2.2 Oe magnetic field data was used, although this does not imply that this is the predominant usage. ${ }^{13-14}$

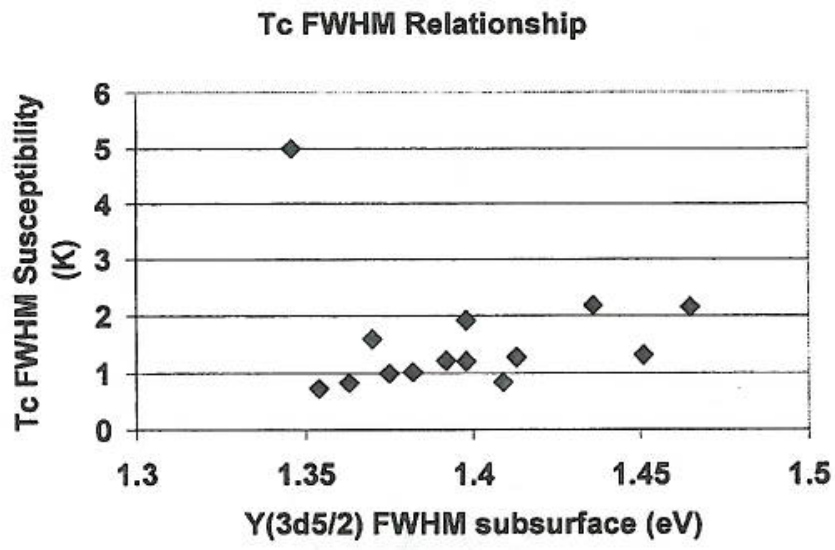

Fig. 5. Comparison of the XPS $Y\left(3 d_{5 / 2}\right)$ FWHM and the $T_{c} F W H M$ determined by ac susceptibility measurement $(2.2 \mathrm{Oe})$. 


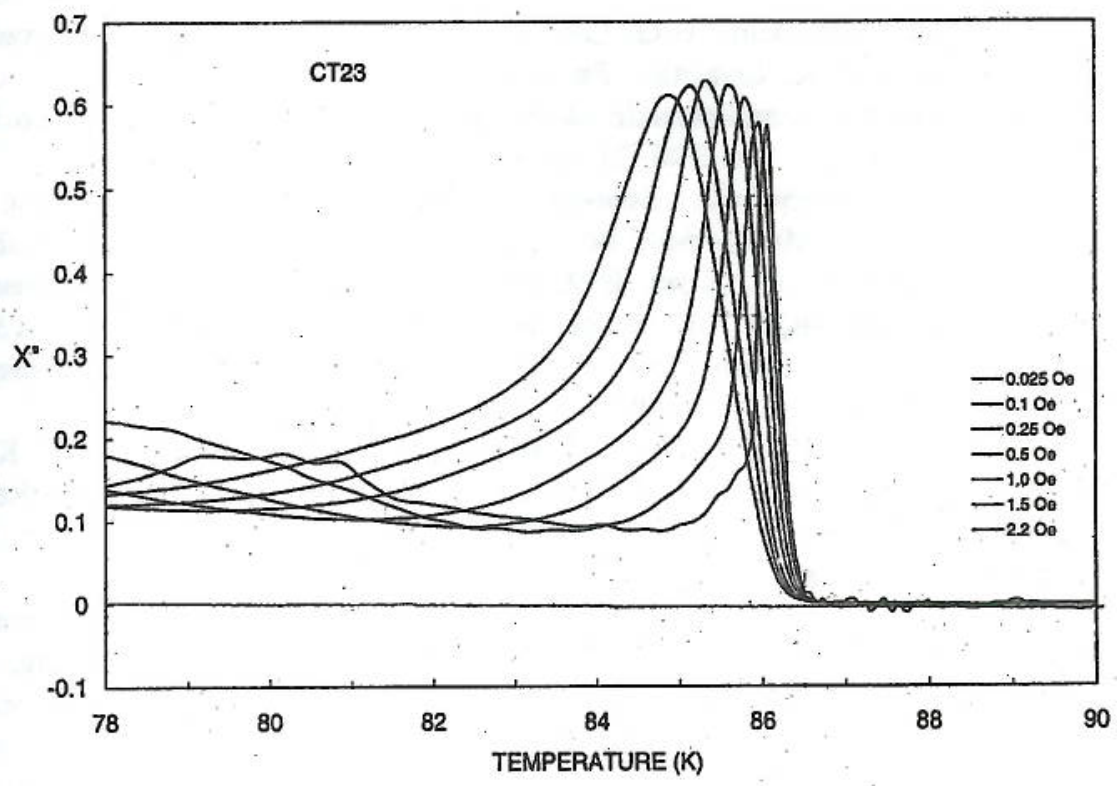

Fig. 6. $\chi^{\prime \prime}$ versus temperature plot of the ac susceptibility data. 0.025 to 2.2 Oe magnetic field used. The different curves result from the different applied fields listed in the legend-the field increases from right to left.

\section{CONCLUSION}

It is seen that the FWHM of certain XPS peaks as well as XPS cationic peak ratios averaged over the analysis area can vary between YBCO samples. A possible correlation of the FWHM of the $\mathrm{Y}\left(3 \mathrm{~d}_{5 / 2}\right)$ XPS peak of YBCO to the thin film quality, specifically the critical transport current density $\left(\mathrm{J}_{\mathrm{c}}\right)$ may exist but is not clear. This relationship is dependent upon the appropriately phased YBCO for a proper comparison and YBCO samples whose nonstoichiometric composition will lead to an alternate XPS spectra. Broadening of the FWHM of the $\mathrm{Y}\left(3 \mathrm{~d}_{5 / 2}\right)$ XPS peak can indicate alternate undesirable bonding in the YBCO. More data is necessary to fully verify these relationships.

\section{ACKNOWLEDGMENT}

The authors gratefully acknowledge the assistance of Lyle Brunke, Julianna Evans, and Timothy Campbell of the Air Force Research Laboratory for their assistance in film preparation, $\mathrm{x}$-ray diagnostics, and making the critical current transport measurements. 


\section{REFERENCES}

${ }^{1}$ V. Selvamanickam, H.G. Lee, Y. Li, X. Xiong, Y. Qiao, J. Reeves, Y. Xie, A. Knoll, and K. Lenseth, "Fabrication of 100 A class, $1 \mathrm{~m}$ long coated conductor tapes by metal organic chemical vapor deposition and pulsed laser deposition," Physica C, 392-396 [2], pp. 859-862 (2003).

${ }^{2}$ D.T. Verebelyi, U. Schoop, C. Thieme, X. Li, W. Zhang, T. Kodenkandath, A.P. Malozemoff, N. Nguyen, E. Siegal, D. Buczek, J. Lynch, J. Scudiere, M. Rupich, A. Goyal, E.D. Specht, P. Martin, and M. Paranthaman, "Uniform performance of continuously processed MOD-YBCO-coated conductors using a textured Ni-W substrate," Superconductivity Science \& Technology, 16, pp. L19-L22 (2003).

${ }^{3}$ J.R. Groves, P.N. Arendt, S.R. Foltyn, Q. Jia, T.G. Holesinger, H. Kung, R.F. DePaula, P.C. Dowden, E.J. Peterson, L. Stan, and L.A. Emmert, "Recent progress in continuously processed IBAD $\mathrm{MgO}$ template meters for HTS applications," Physica C, 382 [1], pp. 43-47 (2002).

${ }^{4}$ A. Goyal, D.F. Lee, F.A. List, E.D. Specht, R. Feenstra, M. Paranthaman, X. Cui, S.W. Lu, P.M. Martin, D.M. Kroeger, D.K. Christen, B.W. Kang, D.P. Norton, C. Park, D.T. Verebelyi, J.R. Thompson, R.K. Williams, T. Aytug, and C. Cantoni, "Recent progress in the fabrication of high- $J_{c}$ tapes by epitaxial deposition of YBCO on RABiTS," Physica C, 357-360 [2], pp. 903-913 (2001).

${ }^{5}$ Air Force Office of Scientific Research High Temperature Superconducting Coated Conductor Review, St. Petersburg, Florida, January 22-24, 2003.

${ }^{6}$ Department of Energy Superconductivity for Electric Systems Annual Peer Review, Washington, DC, July 23-25, 2003.

${ }^{7}$ C.B. Cobb, P.N. Barnes, T.J. Haugan, J. Tolliver, E. Lee, M. Sumption, E. Collings, C.E. Oberly, "Hysteresis loss reduction in striated YBCO," Physica C., 382, pp. 52-56 (2002).

${ }^{8}$ T.J. Haugan, P.N. Barnes, I. Maartense, E.J. Lee, M. Sumption, and C.B. Cobb, "Island growth of $\mathrm{Y}_{2} \mathrm{BaCuO}_{5}$ nanoparticles in $\left(211_{\sim 1.5 \mathrm{~nm}} / 123_{\sim 10 \mathrm{~nm}}\right) \mathrm{xN}$ composite multilayer structures to enhance flux pinning of $\mathrm{YBa}_{2} \mathrm{Cu}_{3} \mathrm{O}_{7-d}$ films," J. Mater. Res., 18, pp.2618-2623 (2003).

${ }^{9}$ T.J. Haugan, M.E. Fowler, J.C. Tolliver, P.N. Barnes, W. Wong-Ng, and L.P. Cook, "Flux Pinning and Properties of Solid-Solution (Y,Nd) ${ }_{1+\mathrm{x}} \mathrm{Ba}_{2-\mathrm{x}} \mathrm{Cu}_{3} \mathrm{O}_{7-\mathrm{d}}$ Superconductors," Ceramic Trans., 140, pp. 299-325 (2003).

${ }^{10}$ P.N. Barnes, S. M. Mukhopadhyay, S. Krishnaswami, T.J. Haugan, J.C. Tolliver, and I. Maartense, "Correlation between the XPS peak shapes of $\mathrm{Y}_{1} \mathrm{Ba}_{2} \mathrm{Cu}_{3} \mathrm{O}_{7-\mathrm{x}}$ and film quality," IEEE Trans. on Appl. Superconductivity, 13, pp. 3643-3646 (2003).

${ }^{11}$ P.N. Barnes, S. Mukhopadhyay, R. Nekkanti, T. Haugan, R. Biggers, and I. Maartense, "XPS depth profiling studies of YBCO layer on buffered substrates," Advances in Cryogenic Engineering, 48B, pp. 614-618 (2002). 
${ }^{12} \mathrm{~J}$. Beyer, Th. Schurig, S. Menkel, Z. Quan, and H. Koch, "XPS investigation of the surface composition of sputtered YBCO thin films," Physica C, 246, pp.156-162 (1995).

${ }^{13}$ I. Maartense and A. K. Sarkar, "Annealing of pressure-induced structural damage in superconducting $\mathrm{Bi}-\mathrm{Pb}-\mathrm{Sr}-\mathrm{Ca}-\mathrm{Cu}-\mathrm{O}$ ceramic," J. Mater. Res., 8, pp. 2177 (1993).

${ }^{14}$ P. N. Barnes, T.J. Haugan, S. Sathiraju, I. Maartense, A.L. Westerfield, R.M. Nekkanti, L.B. Brunke, T.L. Peterson, J.M. Evans, and J.C. Tolliver, "Correlation of AC Loss Data from Magnetic Susceptibility Measurements with YBCO Film Quality," to be presented at MRS Fall Meeting, Boston, MA, December 1-5, 2003. 